University of Nebraska - Lincoln

DigitalCommons@University of Nebraska - Lincoln

1976

\title{
Vertical Profiles of Carbon Dioxide Concentration in Stable Stratification
}

S. B. Verma

University of Nebraska - Lincoln

Follow this and additional works at: https://digitalcommons.unl.edu/natrespapers

Part of the Natural Resources and Conservation Commons, Natural Resources Management and Policy Commons, and the Other Environmental Sciences Commons

Verma, S. B., "Vertical Profiles of Carbon Dioxide Concentration in Stable Stratification" (1976). Papers in Natural Resources. 1210.

https://digitalcommons.unl.edu/natrespapers/1210

This Article is brought to you for free and open access by the Natural Resources, School of at DigitalCommons@University of Nebraska - Lincoln. It has been accepted for inclusion in Papers in Natural Resources by an authorized administrator of DigitalCommons@University of Nebraska - Lincoln. 


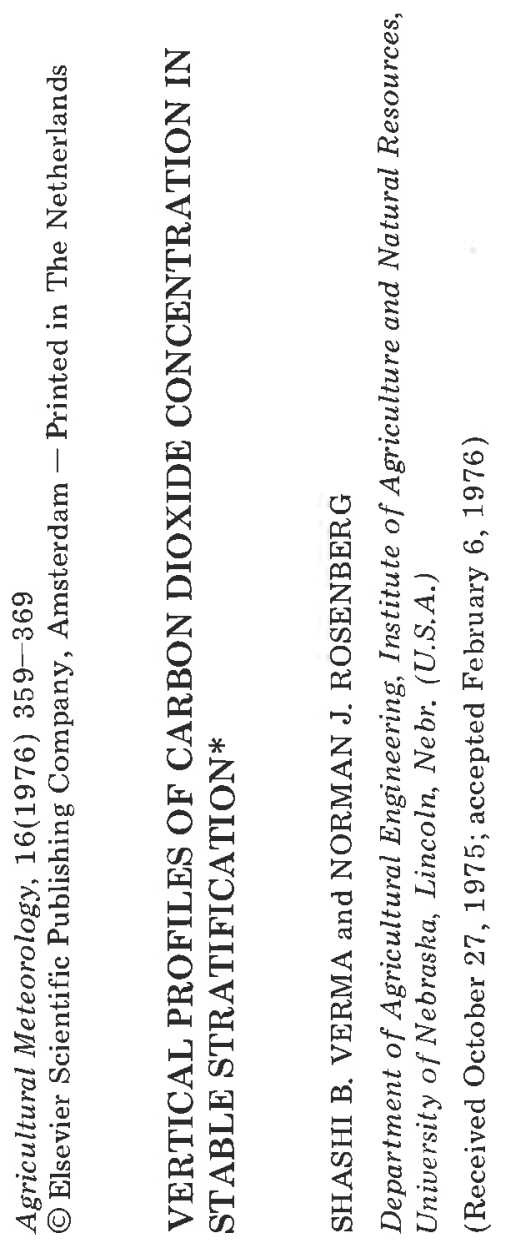

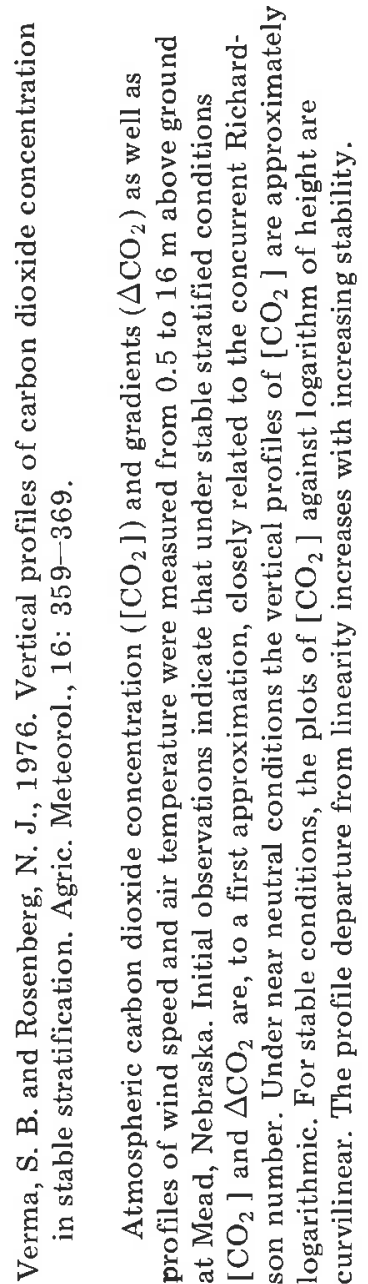

ซ

४

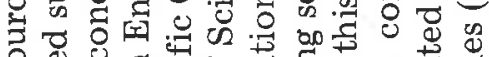
फ 屯ี สี

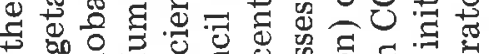
0 00 出 $\lesssim 0$. 范 국

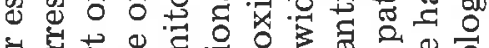

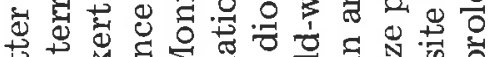
저ㅇㅝㅔ 월 б ठ

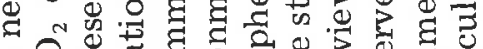

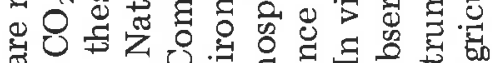
\%

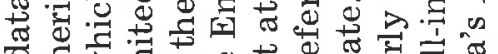
है

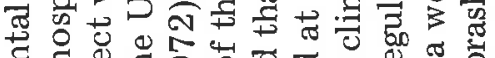

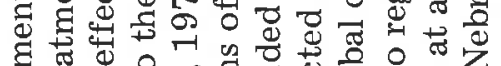
군

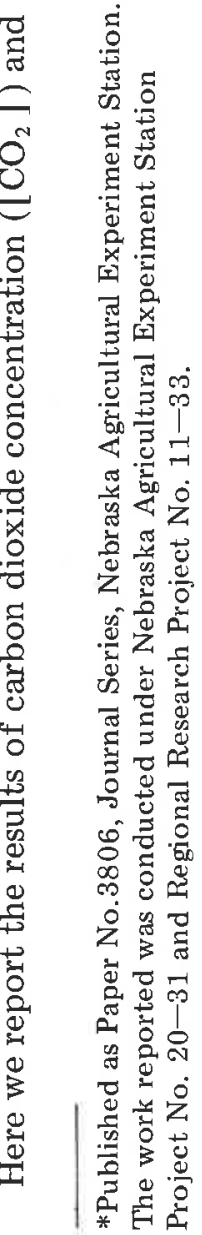




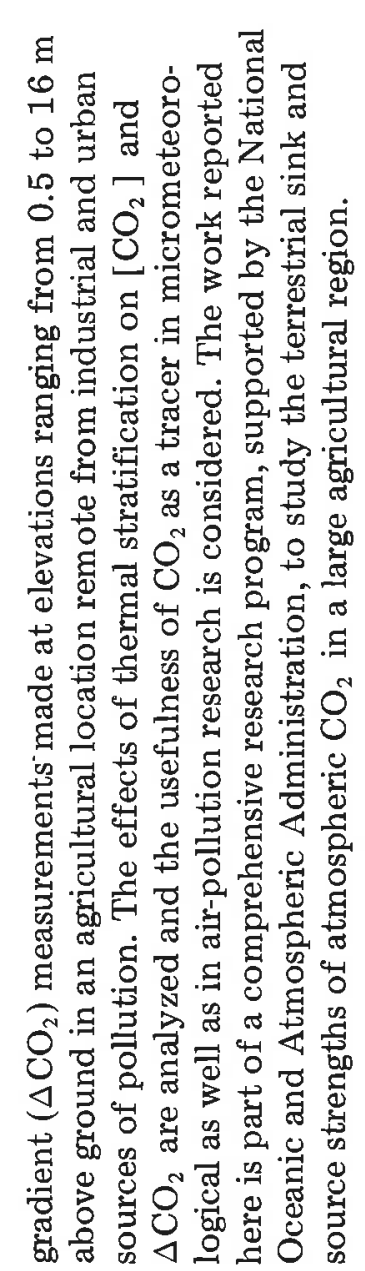

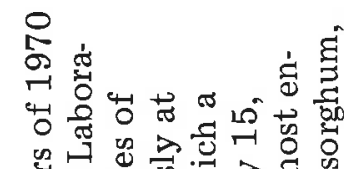

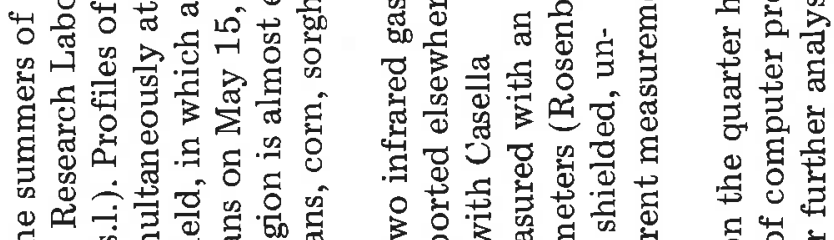

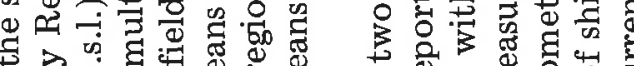

wo

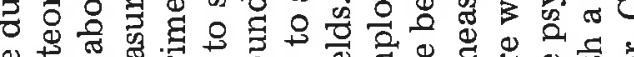

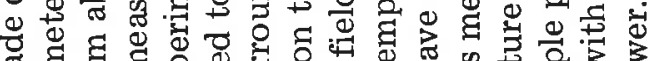

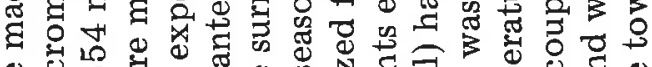
む.

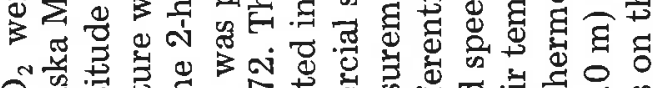

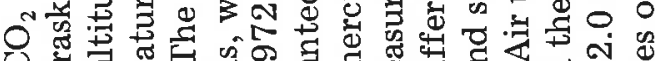

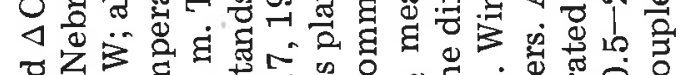
थ

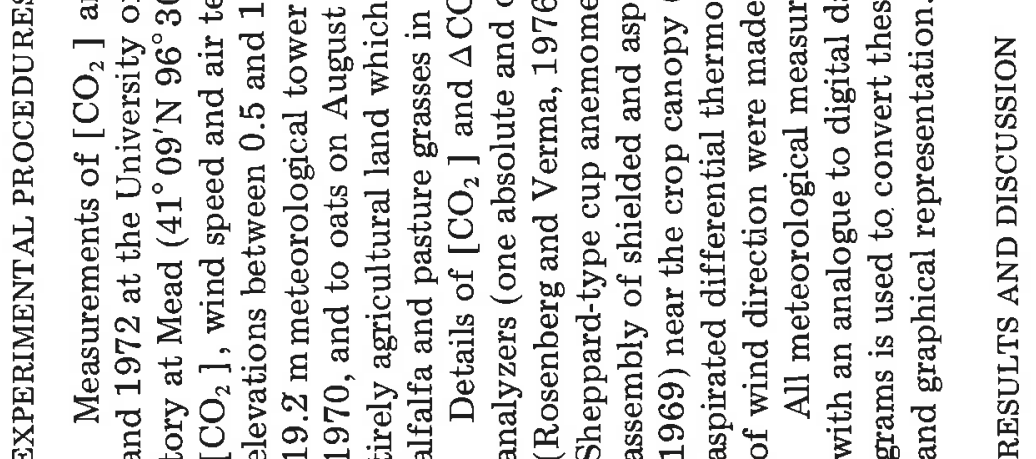

రृ

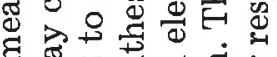

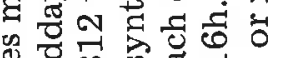

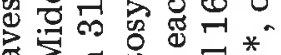

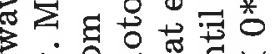
ริ

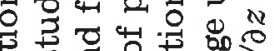

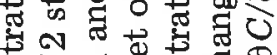
类要 0 -

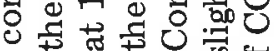
$N$ क \& द का

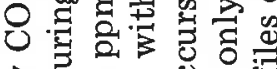
구 $\infty$ \& ซี 컹ํㅀ

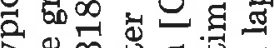

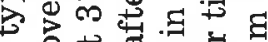

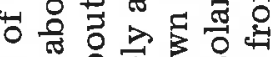

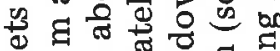
क 6 द्व

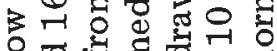
㖇

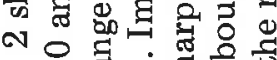

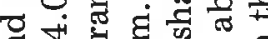
สิ 0 , का - 0 웅

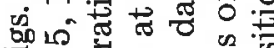
它完营

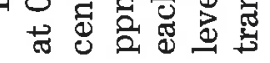



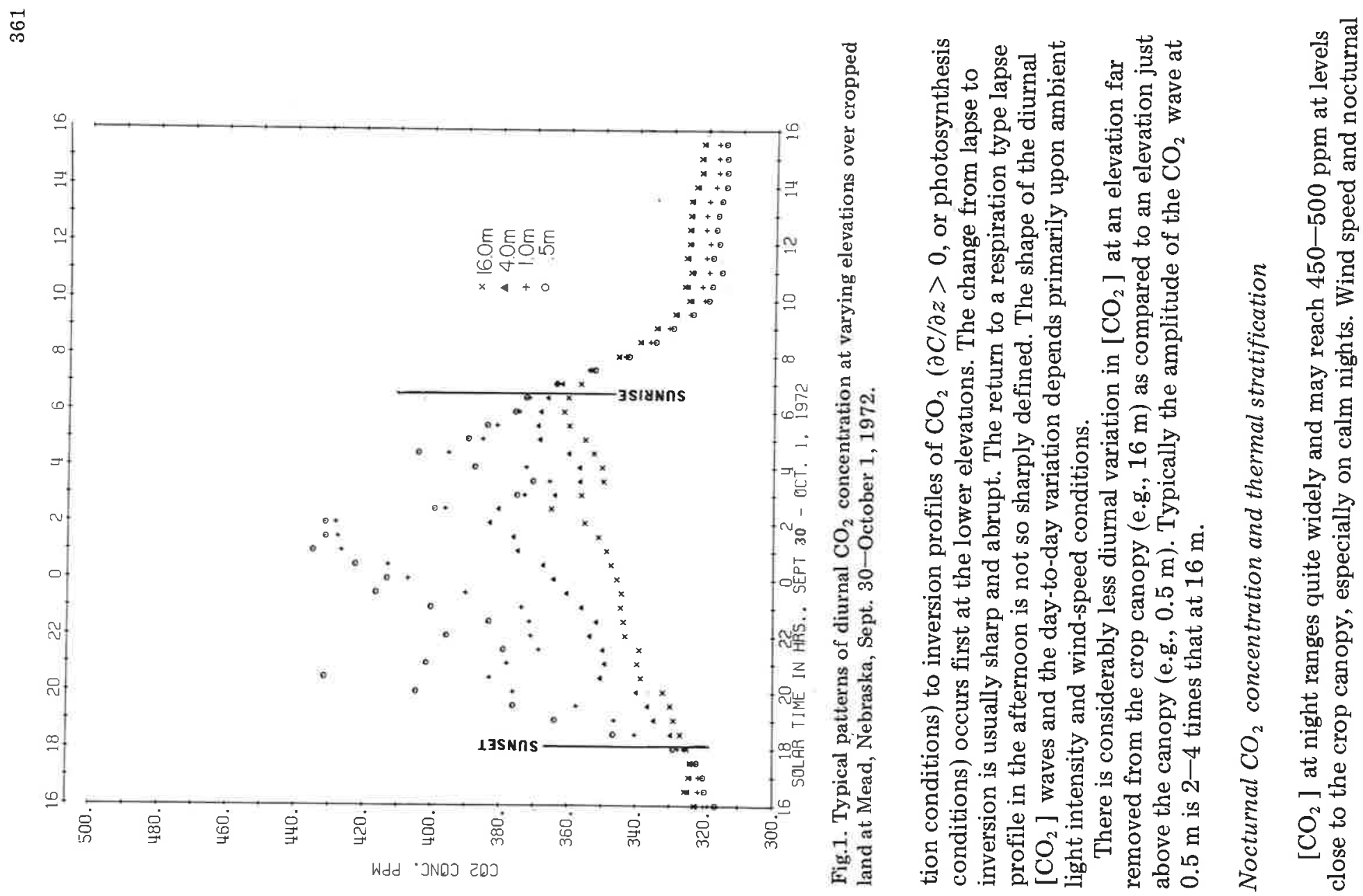


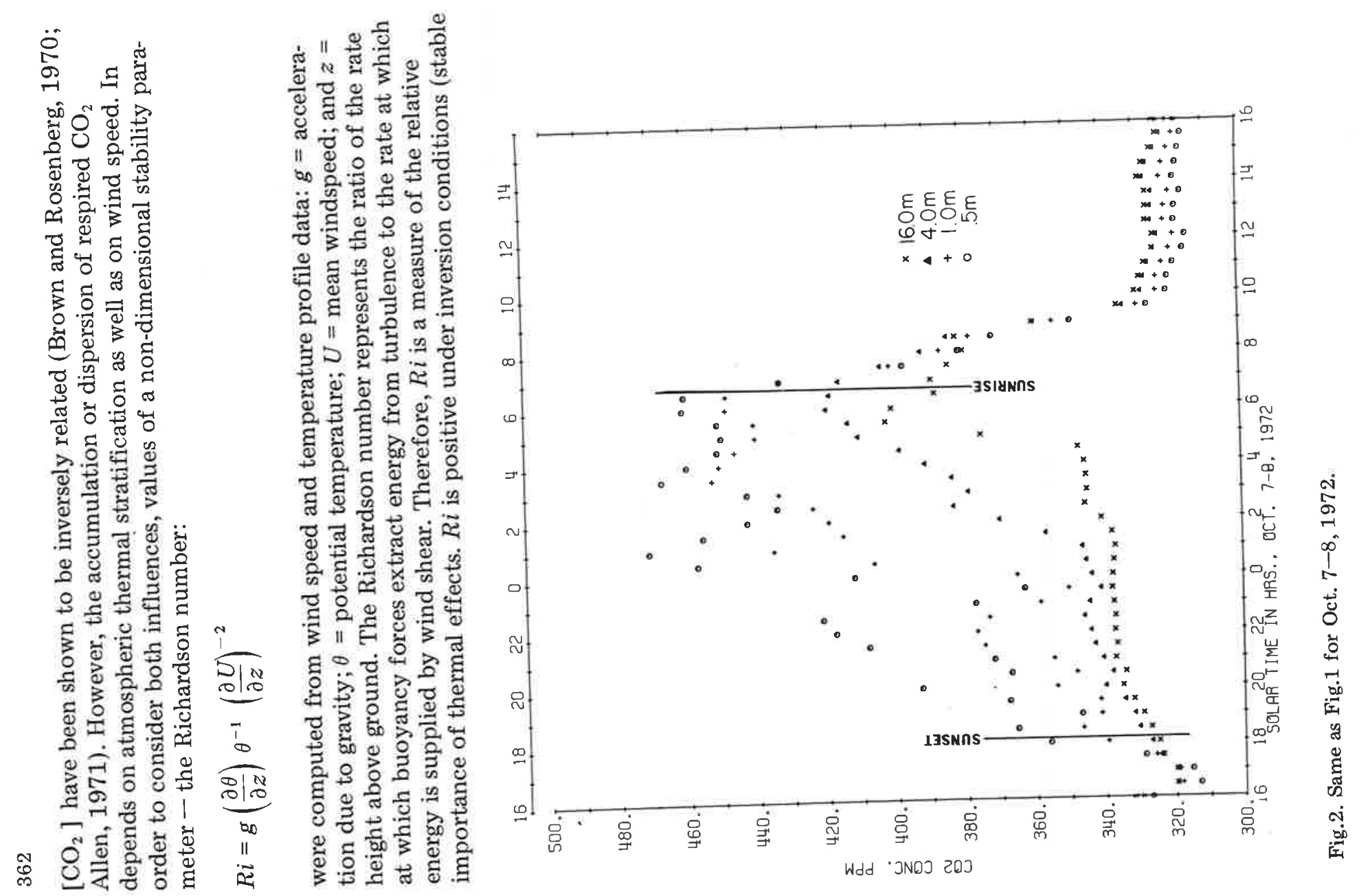



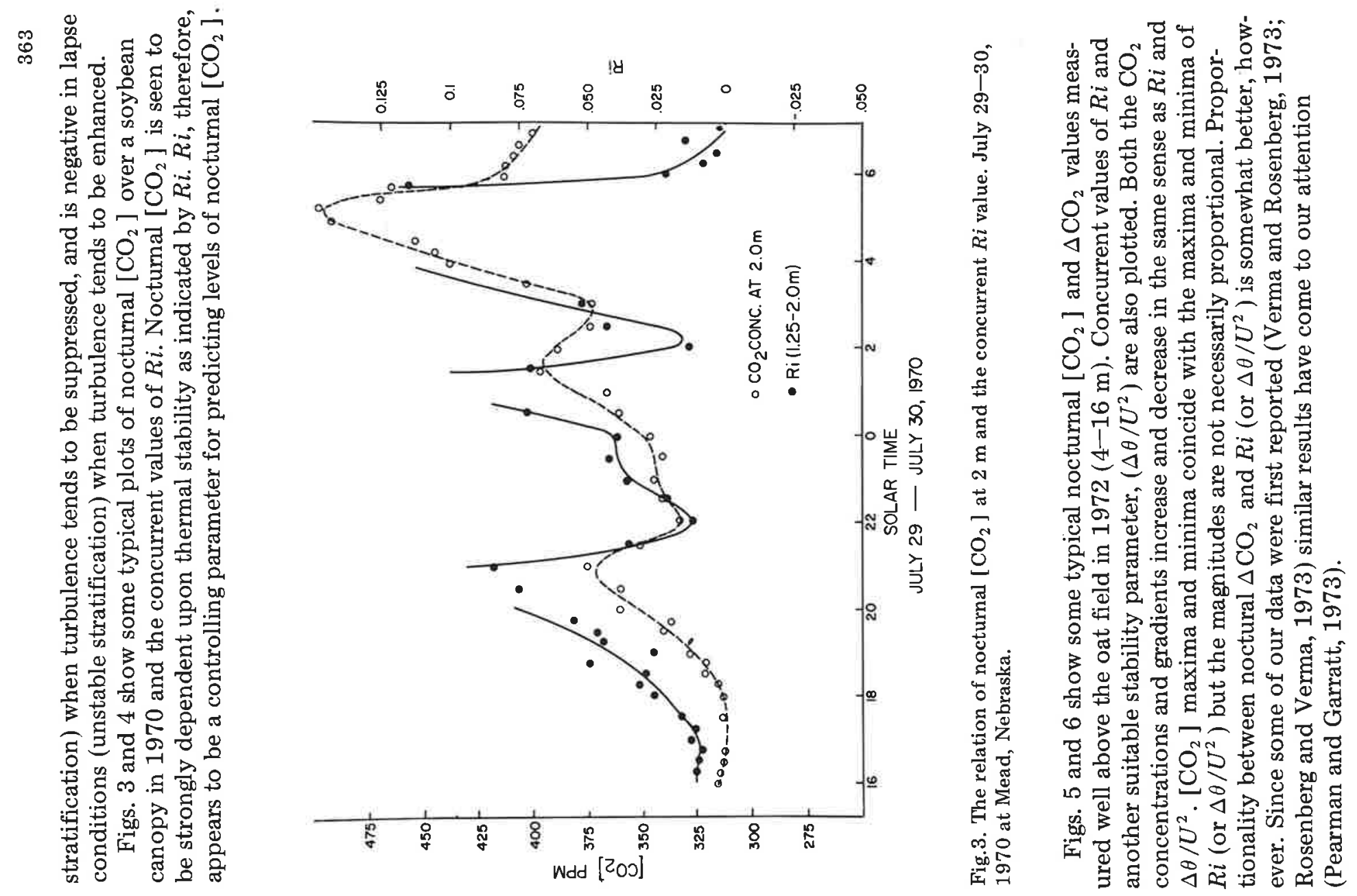


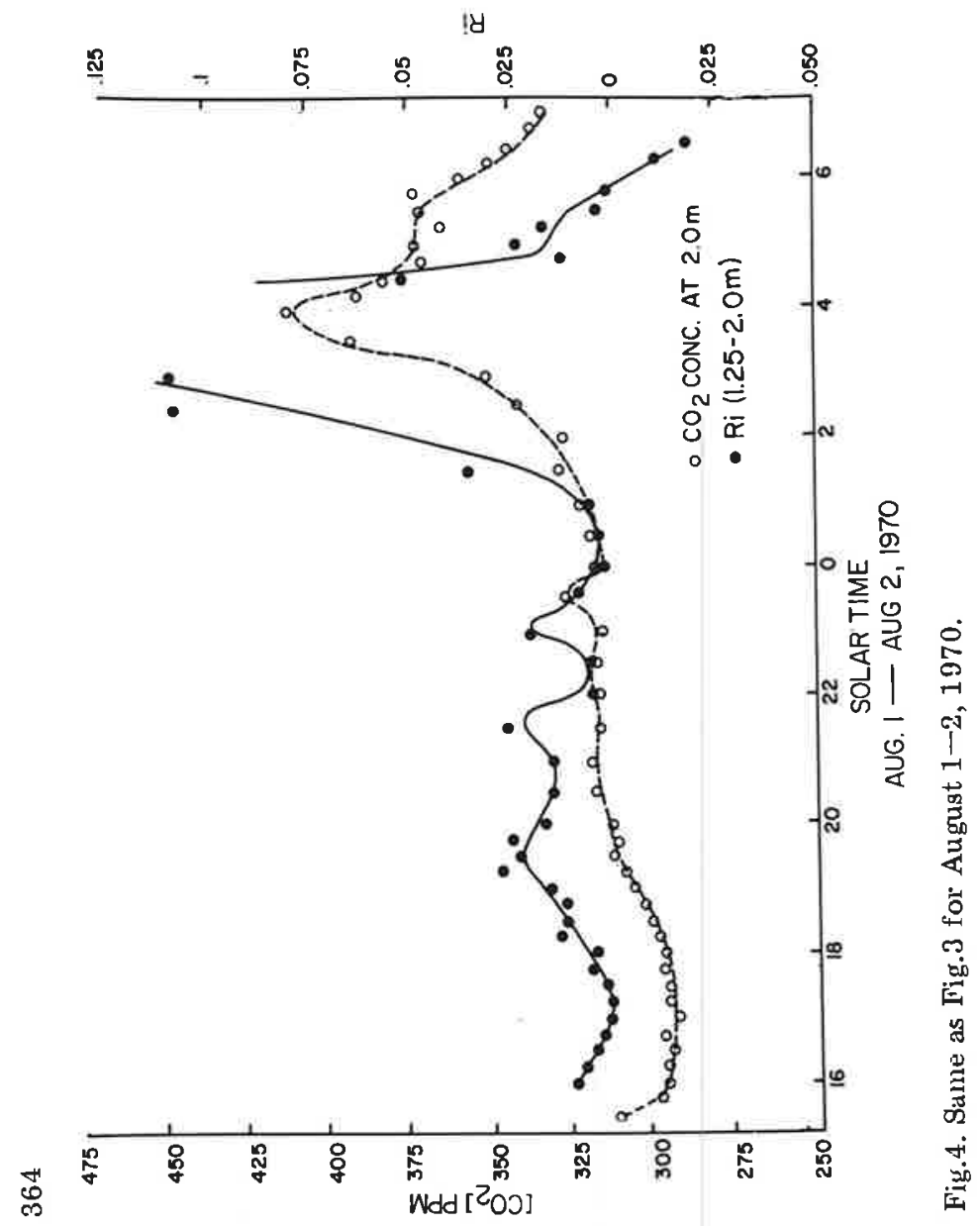

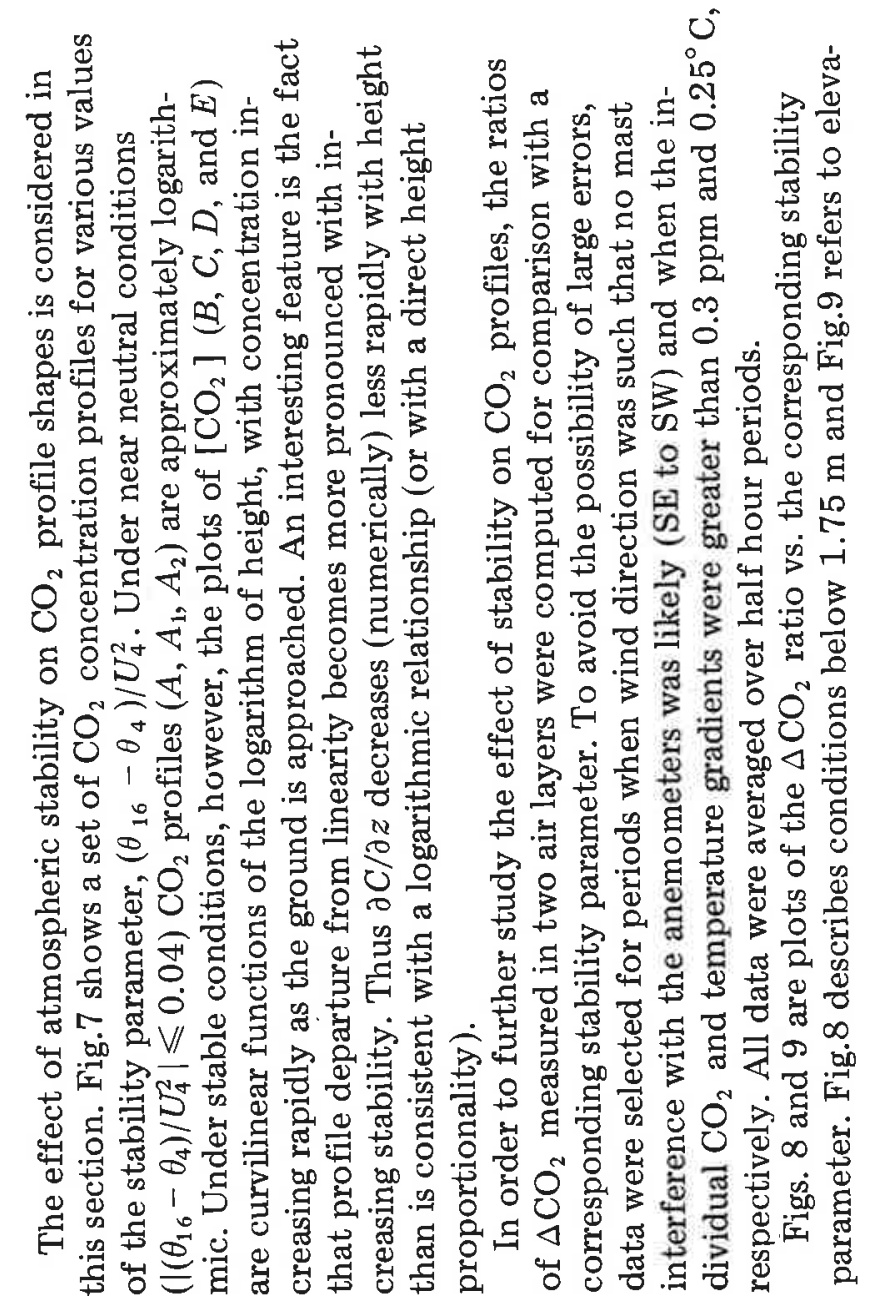


造番苞峞

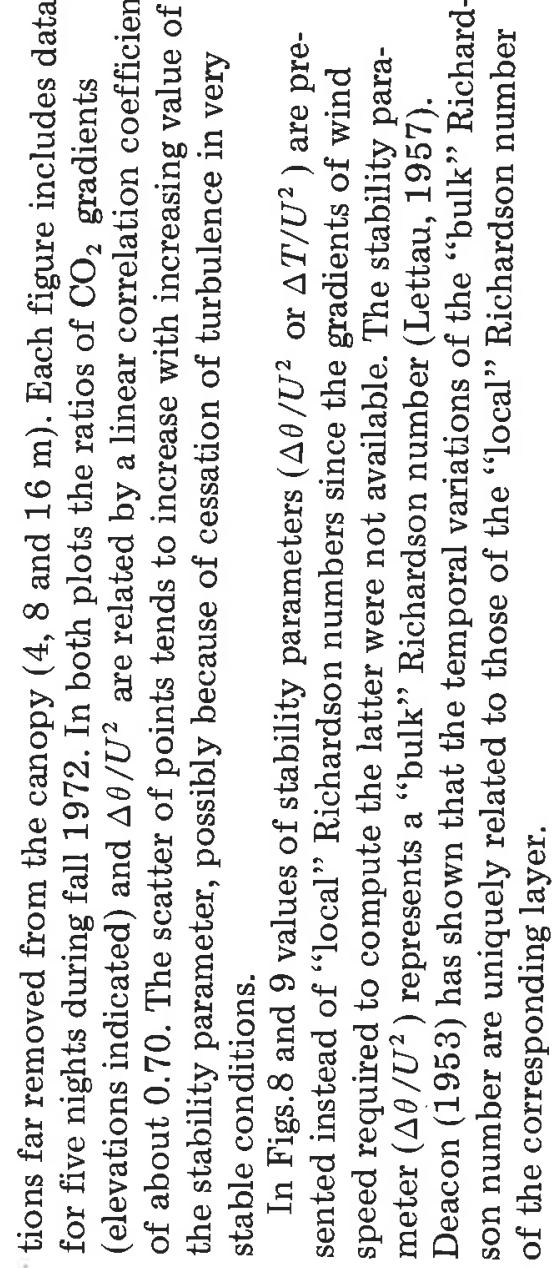

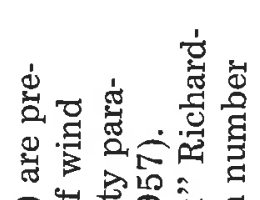
육국 政 $\checkmark:=$ क

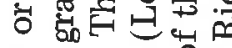
더욛ㅍ

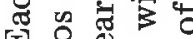

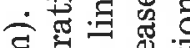
o $\sigma$ 으.二 잉 $\infty$ च व ษ० द 费 类 40

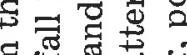
S.

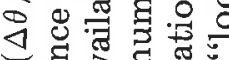
का का है एँ 웅 ह 政. 居 驾势 政 . 에

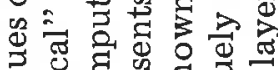

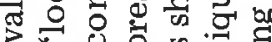
잉 क्ष

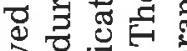
语

w क

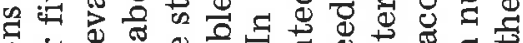

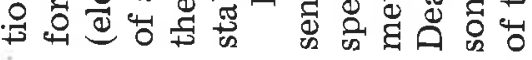

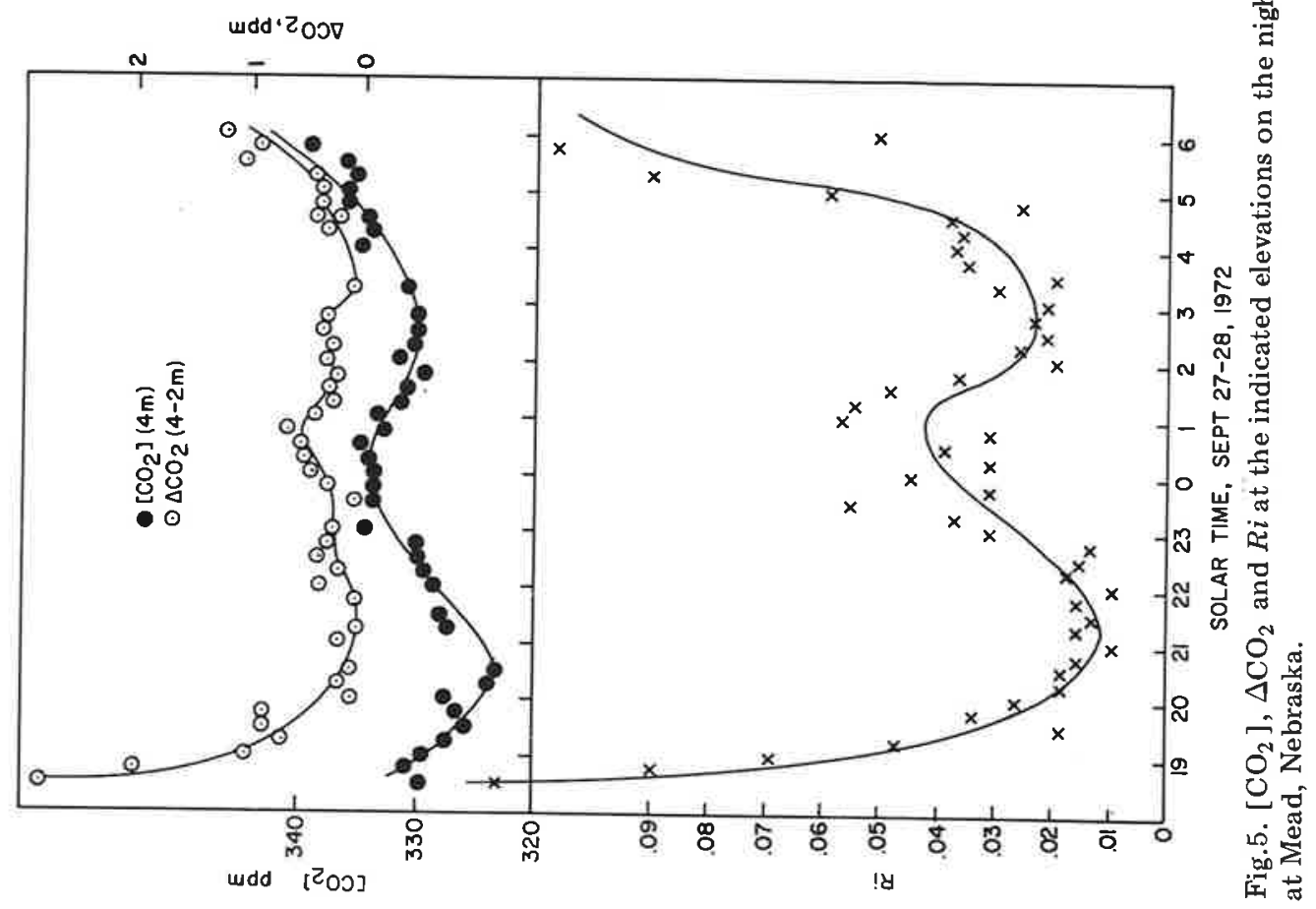



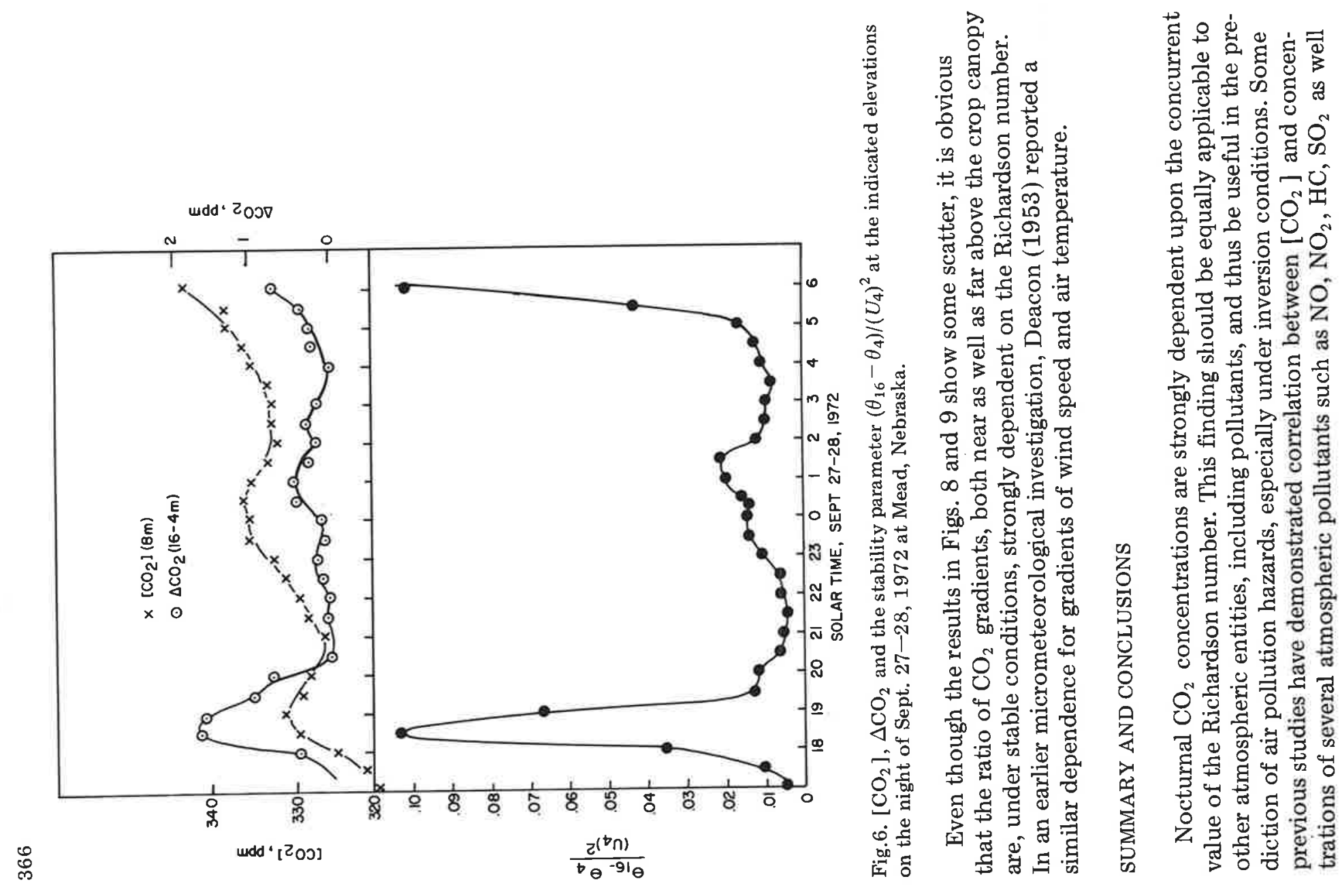


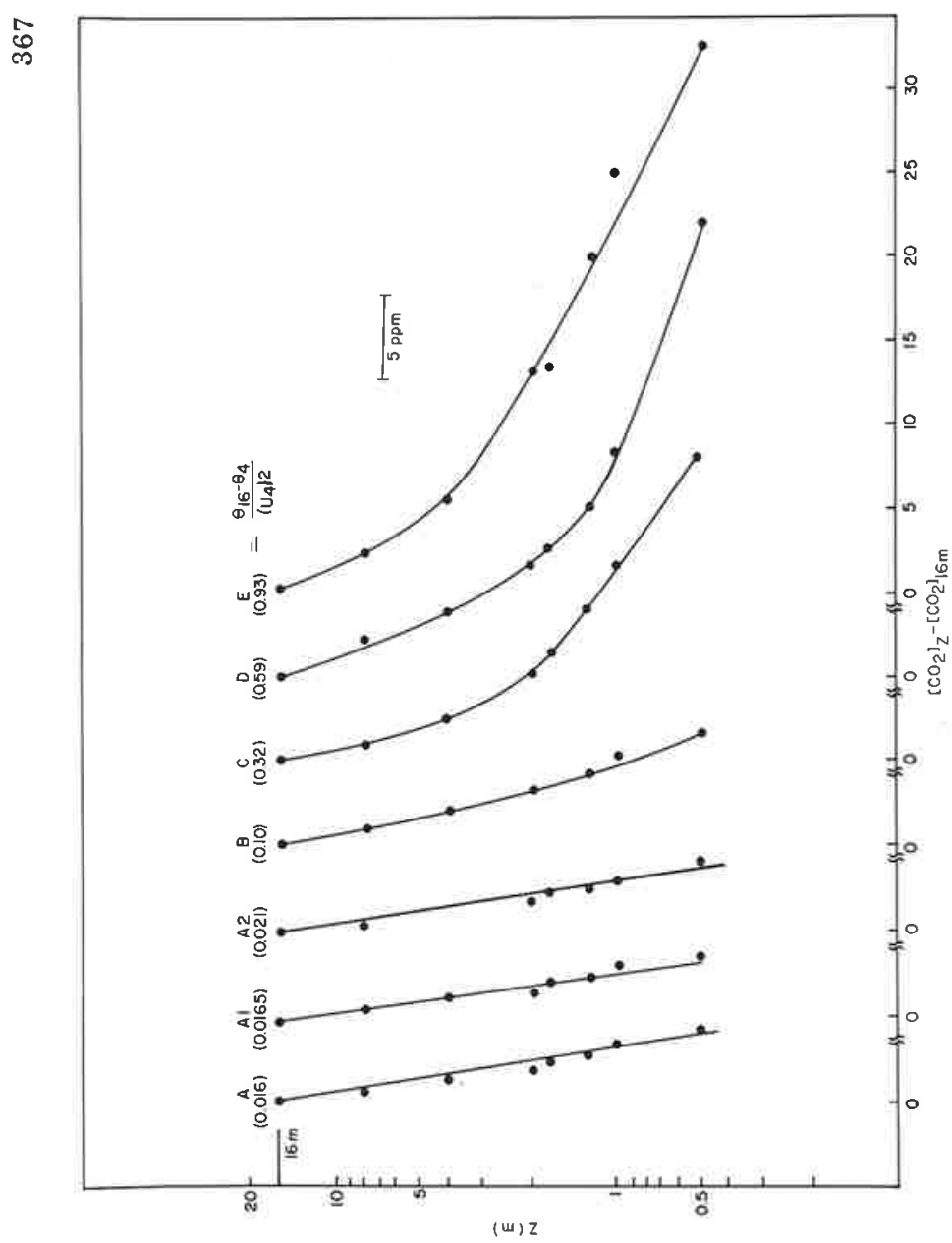

है

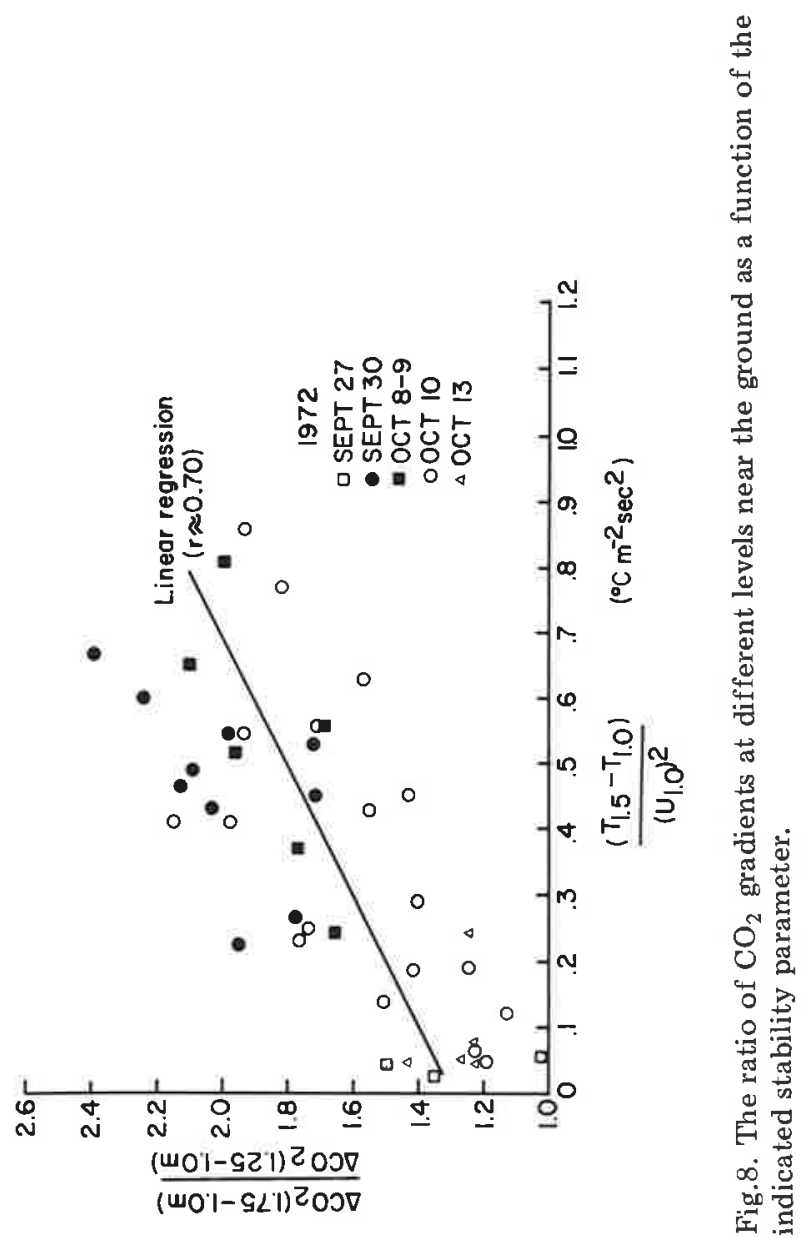



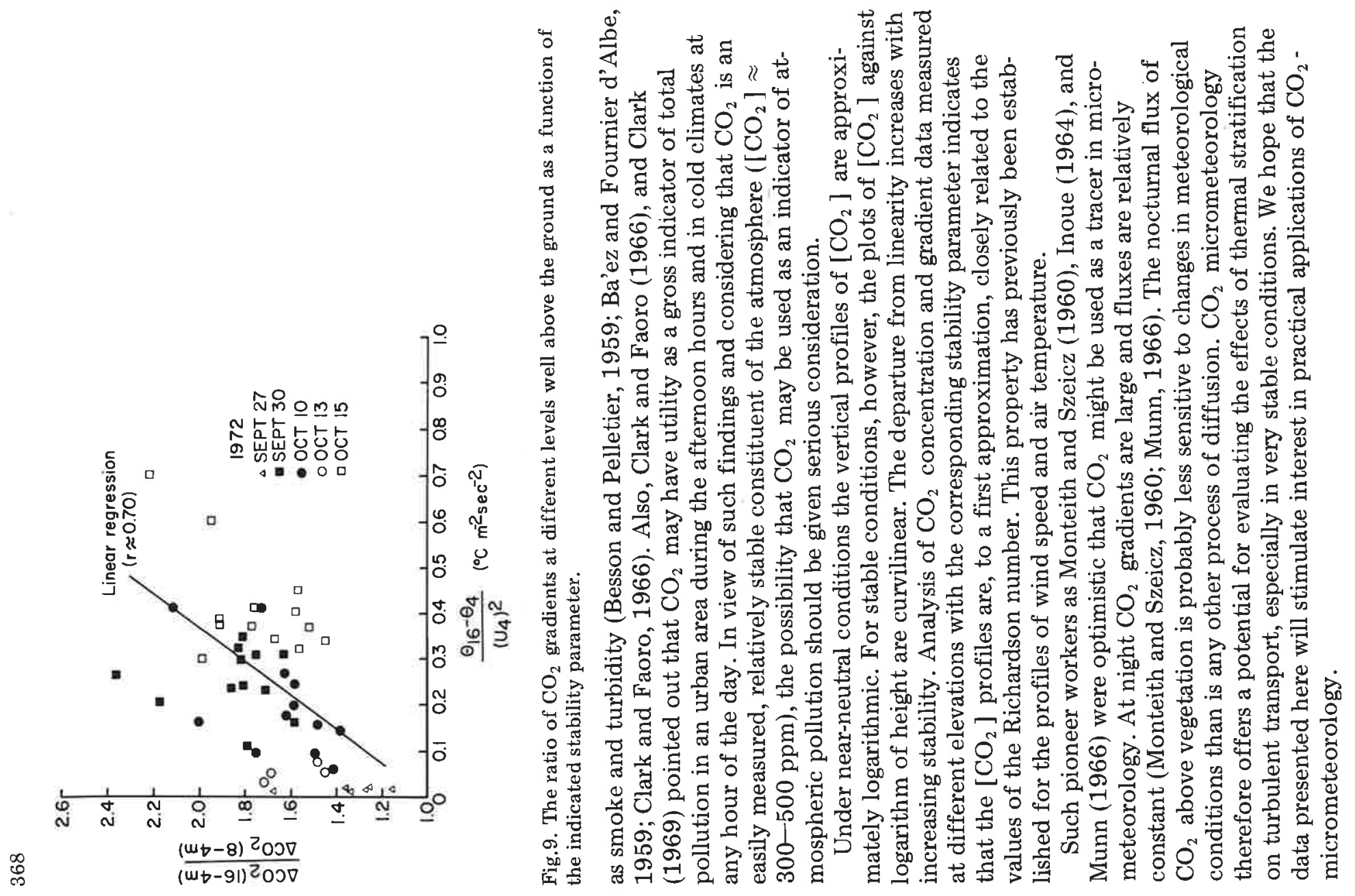


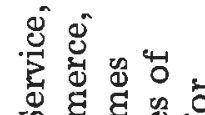

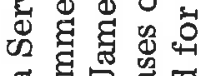
풍 过完 ส] 둥 范家

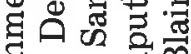

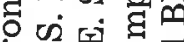

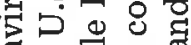

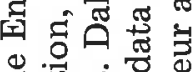
粉

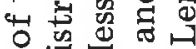
泣 영요 का के दै च 동 동 희흐 훙 व 0 可 政 更冓

兒 ठํㅠ \% 의 क

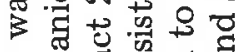
잉 응 용 เ

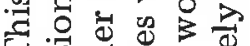

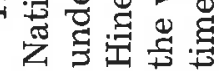

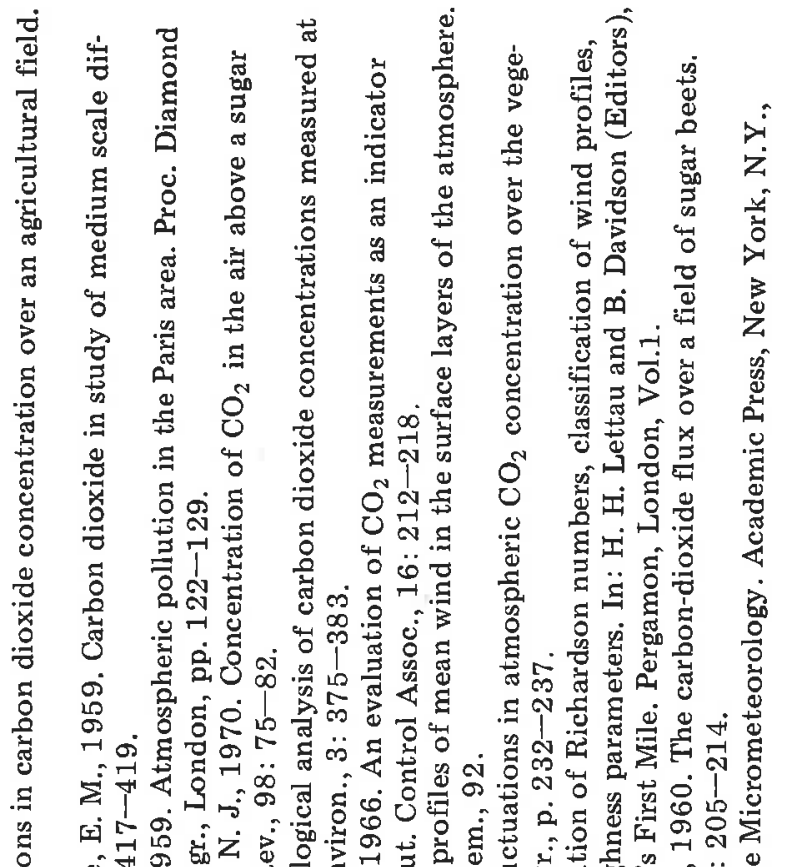

㖼

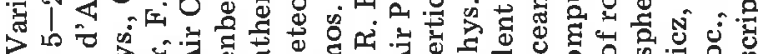

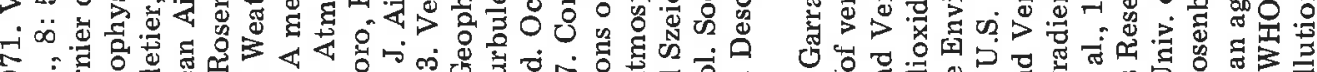

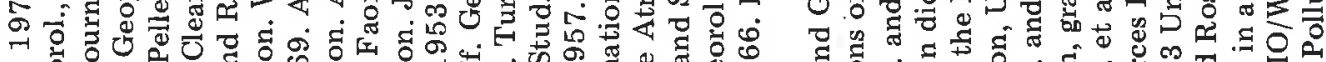

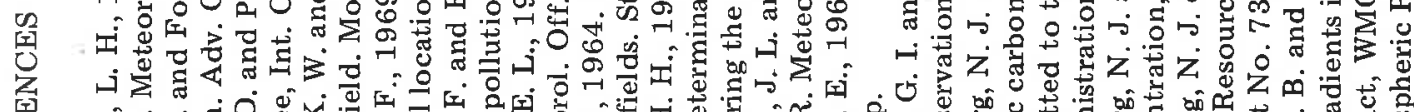

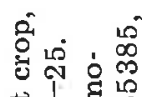

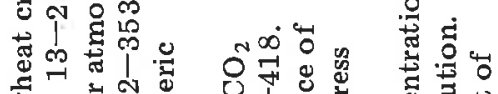

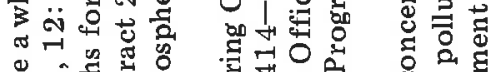

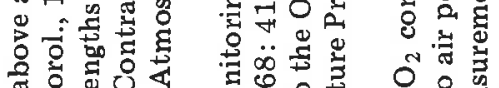

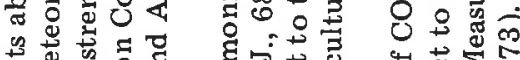

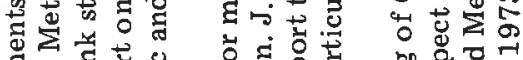

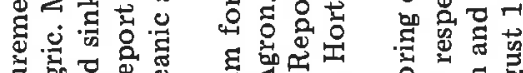

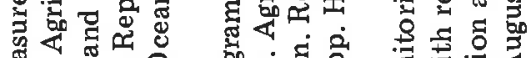
छํ \% 옹

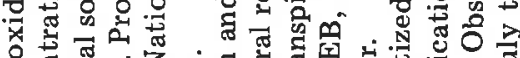

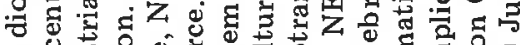
б

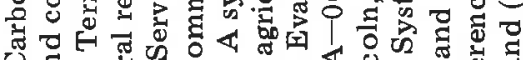
0 的 का

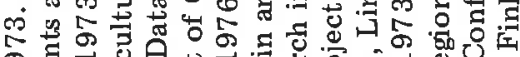
न

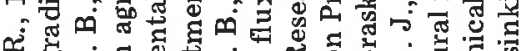

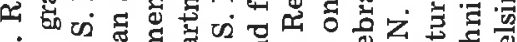
उ สี ส์

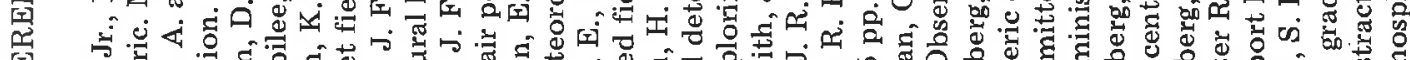

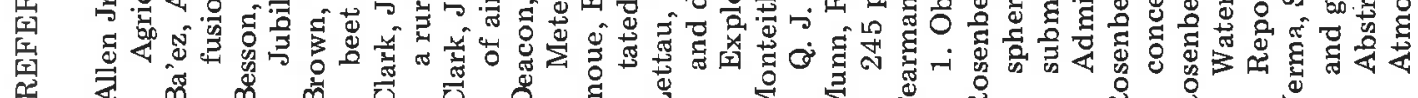


